\title{
Special issue of the 15th Korea-Japan Symposium on Catalysis (15th KJSC)
}

\author{
Jong Wook Bae ${ }^{1} \cdot$ Kwan-Young Lee ${ }^{2}$
}

Published online: 29 January 2016

(C) Springer Science+Business Media Dordrecht 2016

The 15th Korea-Japan Symposium on Catalysis was held in Convention Hall at the Bexco and Haeundae Centum Hotel, Busan, Republic of Korea, from 26 to 28 May 2015. The 15th Korea-Japan Symposium on Catalysis was organized under the supervision of the Division of Catalysis and Reaction Engineering in the Korean Institute of Chemical Engineers (KIChE). This bilateral symposium has been a very successful occasion to deliver information on the recent researches and to have cooperative relationships between scientists and engineers in Korea and Japan. In the symposium, more than 250 papers were presented covering all aspects of catalytic research works from fundamentals and characterizations to various applications extending to green and sustainable technology.

After the peer reviewing process, 26 papers presented in the 15th Korea-Japan Symposium on Catalysis were finally accepted for publication in the special issue of Research on Chemical Intermediates. Some interesting aspects of the heterogeneous catalysts related to green and sustainable technologies were included in this special issue. On behalf of the organizing committee listed below, the committee members would like to appreciate the enthusiastic contributions of all participants for the success of the 15th Korea-Japan Symposium on Catalysis in Korea.

- Chair: Prof. Kwan-Young Lee (Korea University)

- Vice-Chair: Prof. Jong-Ki Jeon (Kongju National University)

- Japanese coordinator: Prof. Atsushi Muramatsu (Tohoku University)

- Secretary: Prof. In Kyu Song (Seoul National University)

Jong Wook Bae

finejw@skku.edu

1 Sungkyunkwan University (SKKU), Suwon, Republic of Korea

2 Korea University, Seoul, Republic of Korea 
- Program Chair: Prof. Sung June Cho (Chonnam National University)

Prof. Do Heui Kim (Seoul National University)

Prof. Jong Wook Bae (Sungkyunkwan University)

Dr. Jung-Il Yang (Korea Institute of Energy Research)

- Sponsorship: SK innovation Co., Ltd and MicrotracBEL \& Soletek Trading Co., Ltd 